\title{
Potensi Pengembangan Budidaya Pada Kawasan Konservasi Perairan Datok Bandar Kabupaten Lingga
}

\author{
Tengku Said Razai ${ }^{1^{*}}$, Fitria Ulfah ${ }^{2,{ }^{*}}$, Febrianti Lestari $^{3}$, Dony Apdillah $^{4}$, Ita Karlina ${ }^{5}$, \\ Fadliyah Idris $^{6}$, Try Febrianto ${ }^{7}$ \\ ${ }^{1}$ Jurusan Budidaya Perikanan, Fakultas Ilmu Kelautan dan Perikanan, Universitas Maritim Raja Ali Haji, \\ Tanjungpinang, Indonesia. \\ ${ }^{2}$ Jurusan Sosial Ekonomi Perikanan, Fakultas Ilmu Kelautan dan Perikanan, Universitas Maritim Raja Ali \\ Haji, Tanjungpinang, Indonesia. \\ ${ }^{3}$ Jurusan Manajemen Sumberdaya Perairan, Fakultas Ilmu Kelautan dan Perikanan, Universitas Maritim \\ Raja Ali Haji, Tanjungpinang, Indonesia. \\ 4, 5, 6,7 Jurusan Ilmu Kelautan, Fakultas Ilmu Kelautan dan Perikanan, Universitas Maritim Raja Ali Haji, \\ Tanjungpinang, Indonesia. \\ *Koresponden E-mail: ulfahfitria@umrah.ac.id and tengku.saidrazai@gmail.com
}

(Diterima 25 Februari 2021|Disetujui 24 Juni 2021|Diterbitkan 18 Juli 2021)

\begin{abstract}
The development of aquaculture in the Marine Protected Area (KKP) has to recognize the sustainability and the balancing of the ecosystem in that area. It causes limited rights of users who want to develop their business, where the issuance of permits and business management regulations is an obligation that must be followed by aquaculture business developers in the KKP area. The study aimed was to formulate the technical directions in developing the potential for aquaculture business in the Marine Protected Area of Datok Bandar (KKPD) at Lingga Regency. The method used in this research is a descriptive quantitative using analysis of the carrying capacity of the environment for aquaculture, water quality parameters, and a participatory approach. The results showed that the potential area to be developed for aquaculture was 3,736.01 ha. However, based on the carrying capacity analysis, only 268,420 ha or 7.2\% from the existing potential can be utilized for aquaculture. Furthermore, based on the water quality measurements for aquaculture, the KKPD area was divided into 3 designations groups of aquaculture areas, namely the KJT, KJA, and seaweed. The number of aquaculture business units that were allowed in this area was 16,776 units consisting of 10,066 small business units and 6,710 medium business units with 7 types of superior fish. The limitation of land area and some business units in conservation areas were important to ensure the sustainability of the environment in the future. The implication of this research could be used as a basis for issuing aquaculture business permits, and to ensure that small-scale aquaculture fishermen have a large proportion. In addition to ensuring the existence of local communities who were generally small farmers, conservation areas were very vulnerable to environmental changes, so the risk factors and impacts of business utilization were important to consider.
\end{abstract}

Keywords: Aquaculture, Marine protected area, Carrying capacity, Lingga Regency

\section{PENDAHULUAN}

Pemanfaatan Kawasan Konservasi Perairan (KKP) untuk kegiatan budidaya terdapat dapat Peraturan Dirjen Pengelolaan Ruang Laut (PRL) Kementerian Kelautan dan Perikanan No. 03 Tahun 2016. Akan tetapi, pelaksanaan pengembangan budidaya perikanan di daerah KKP memiliki perbedaan dengan daerah non KKP. Pada daerah KKP, aspek keberlanjutan, kelestarian, dan keseimbangan ekosistem menjadi prioritas utama agar manfaat ekosistem dapat terus dirasakan oleh masyarakat dari masa ke masa (Firdaus \& Sari, 2010; Rajab et al., 2013; Affan, 2012; Nordiansyah et al., 2016). Budidaya perikanan di daerah konservasi juga diharapkan dapat mempertahankan kelestarian spesies endemik daerah (Bato et al., 2013). Oleh karenanya budidaya di daerah konservasi tidak hanya mengedepankan profit melalui hasil produksi semata (Purnawan et al., 2015), tetapi juga dapat diperoleh melalui kegiatan ekowisata budidaya yang dikembangkan.
Akan tetapi, kegiatan budidaya di kawasan konservasi memiliki faktor resiko yang sangat rentan terhadap perubahan lingkungan. Disamping itu, kegiatan pemanfaatan budidaya di wilayah konservasi juga dapat menimbulkan dampak secara sosial, ekonomi dan ekologi apabila tidak ada pedoman yang mengaturnya (Bato et al., 2013; Peranginangin, 2014).

Penguasaan wilayah budidaya membutuhkan modal yang besar sehingga hanya dapat dimiliki oleh para pengusaha besar. Lokasi budidaya yang dilakukan pada zona inti/zona perlindungan laut dapat mengganggu keseimbangan dan kelestarian ekosistem. Kondisi tersebut merupakan beberapa contoh dampak yang dapat terjadi dalam kegiatan budidaya di wilayah konservasi. Oleh karenanya perlu adanya arahan teknis yang mengatur kegiatan pemanfaatan budidaya di wilayah KKP.

Arahan teknis kegiatan pemanfaatan budidaya di wilayah KKP dapat digunakan sebagai pedoman dalam pengelolaan budidaya di wilayah konservasi (Hakim et al., 2014). Dimana arahan teknis tersebut mengatur hak-hak pengusaha yang ingin mengem- 
bangkan usaha budidayanya di wilayah KKP. Aturan tersebut juga diharapkan dapat mengembangkan pemanfaatan budidaya berbasis masyarakat, sehingga porsi pengembangan budidaya terbesar diperuntukan bagi pengusaha kecil dan menengah.

Disamping itu, arahan teknis pemanfaatan kegiatan budidaya di kawasan konservasi diharapkan juga dapat mengatur agar lokasi budidaya hanya diperbolehkan di daerah yang telah ditetapkan, dengan luasan wilayah sesuai dengan kemampuan perbaikan secara alami. Hal ini dilakukan agar kegiatan budidaya di wilayah KKP selaras dengan upaya konservasi yang dilakukan. Dengan demikian, arahan teknis tersebut dapat memberikan kepastian agar eksistensi masyakat lokal yang umumnya pembudidaya kecil dapat terjamin, serta memperkecil resiko dan dampak lain yang timbul dari pemanfataan usaha budidaya.

Dalam merumuskan arahan teknis tersebut, selain membutuhkan data ekologis wilayah, juga dibutuhkan informasi dari masyarakat yang berada di sekitar wilayah konservasi terhadap keinginan dan kebutuhan mereka dalam melakukan budidaya. Hal ini dimaksudkan agar arahan yang dirumuskan bersifat bottom up, sehingga dapat memunculkan rasa memiliki dan inisisatif dari masyarakat untuk ikut serta menjaga kawasan konservasi (Pranata \& Satria, 2015; Utami \& Pancasilawan, 2017).

Penelitian ini bertujuan untuk merumuskan arahan teknis dalam mengembangkan potensi usaha budidaya perikanan pada kawasan konservasi perairan, dengan mengambil wilayah Kawasan Konservasi Perairan Daerah (KKPD) Datok Bandar Kabupaten Lingga sebagai lokasi penelitian. Hasil penelitian diharapkan dapat digunakan sebagai dasar penerbitan izin pemanfaatan wilayah KKPD untuk kegiatan budidaya, dan memberi kepastian bagi kelompok pembudidaya skala kecil agar dapat memiliki proporsi yang besar dalam kegiatan pemanfataan budidaya di wilayah konservasi.

\section{BAHAN DAN METODE}

\section{Lokasi dan waktu penelitian}

Penelitian dilakukan di tujuh desa yang tersebar di dua kecamatan Kabupaten Lingga. Lima (5) desa terdapat di Kecamatan Senayang, yaitu Desa Benan, Desa Tajur Biru, Desa Mamut, Desa Pena'ah, dan Desa Batu Belubang. Dua (2) desa lainnya yaitu Desa Limbung dan Desa Sekanah, terdapat di Kecamatan Lingga Utara (Gambar 1). Pemilihan lokasi dilakukan secara purposive, dengan pertimbangan bahwa wilayah perairan di ketujuh desa tersebut termasuk ke dalam KKPD Datok Bandar Kabupaten Lingga. Penelitian dilakukan pada Bulan September - November 2016.

\section{Analisis Data}

Data yang diperoleh dianalisis secara deskriptif kuantitatif. Analisa yang digunakan adalah pengukuran kualitas air untuk kawasan budidaya (Yulianda, 2008; Novita et al., 2015; Alifatri et al., 2017), serta daya dukung kawasan budidaya berdasarkan perhitungan asimilasi oksigen terlarut (Mansur et al., 2013).
Sedangkan pendekatan partisipatoris dilakukan dalam bentuk Focus Group Discussion/FGD, teknik pengumpulan informasi dan teknik visualisasi (Moerad et al., 2014; Syahrani, 2016).

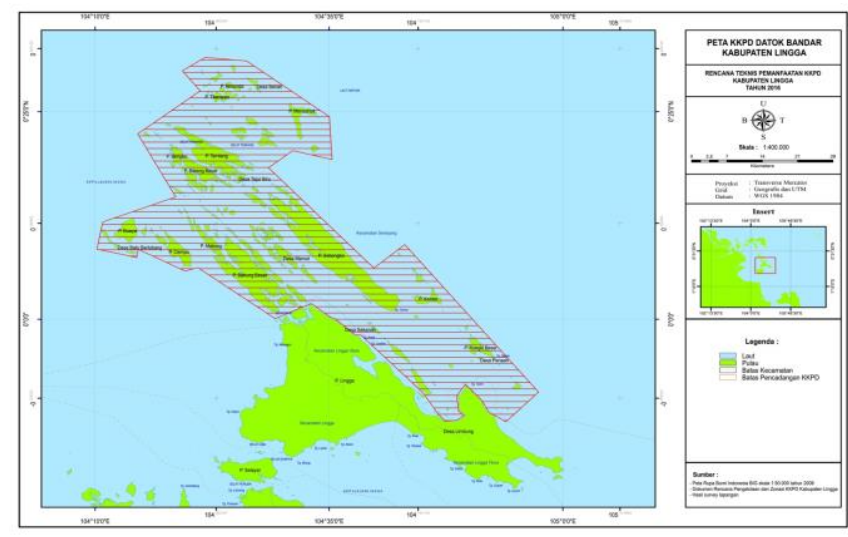

Gambar 1. Lokasi Penelitian di Wilayah KKPD Datok Bandar Kabuaten Lingga

\section{Metode Pengumpulan Data}

Data yang digunakan dalam penelitian ini adalah adalah data primer yang diperoleh secara langsung dengan mengambil sampel dari wilayah KKPD Datok Bandar, serta data sekunder yang diperoleh dari hasil kajian, rencana zonasi daerah, pedoman penyusunan rencana teknis pemanfataan kawasan konservasi, Dinas Perikanan Kabuaten Lingga, Badan Pusat Statistik Kabupaten Lingga, serta literatur terkait lainnya. Adapun data primer yang diambil adalah : (1) Data parameter kualitas air mencakup salinitas, suhu, kecerahan, $\mathrm{pH}, \mathrm{DO}$, kecepatan arus, tinggi gelombang, kedalaman, BOD, nitrat, nitrit, pospat, dan klorofil A, dan (2) Data daya dukung kawasan budidaya.

Data kualitas air yang diukur secara insitu yakni salinitas, suhu, $\mathrm{pH}, \mathrm{DO}$, arus, dan kedalaman. Salinitas diukur dengan alat refractometer, sedangkan suhu, $\mathrm{pH}$, dan DO diukur dengan multitester. Arus diukur dengan menggunakan current meter, dan . kedalaman diukur dengan fishfinder. Data kualitas air yang diukur secara eksitu meliputi nitrit, nitrat, fosfat, dan klorofil-A menggunakan metode spektrofotometri.

Data primer juga diperoleh dengan menggunakan pendekatan partisipatoris (Participatory Rural Appraisal). Metode ini digunakan untuk memperoleh informasi dari sudut pandang masyarakat mengenai kondisi sosial, ekonomi, dan ekologi mencakup jenis-jenis ikan, lokasi budidaya, benih dan pakan ikan, teknologi yang digunakan, serta norma dan budaya yang terdapat di desa. Adapun responden dalam penelitian ini adalah nelayan, pokmaswas, dan aparat desa.

\section{Daya Dukung Kawasan (Carrying Capacity)}

Penentuan daya dukung kawasan dilakukan berdasarkan ketersediaan oksigen terlarut dimana perbedaan antara konsentrasi oksigen $\left(\mathrm{O}_{2}\right)$ terlarut minimal yang dikehendaki oleh organisme $\left(\mathrm{O}_{\text {in }}\right)$ dengan kadar oksigen yang tersedia didalam perairan $\left(\mathrm{O}_{\text {out }}\right)$. Kadar minimum yang dikehendak adalah sebesar $4 \mathrm{ppm}$ (Mansur et al., 2013). 
$\left(\mathrm{O}_{2}\right)=\mathrm{Q}_{0} \times 1440$ menit/hari $\mathrm{x}\left(\mathrm{O}_{\text {in }}-\mathrm{O}_{\text {out }}\right)$ $=\mathrm{X} \mathrm{Kg} \mathrm{O}_{2}$

Dimana

$\mathrm{Q}_{0}=$ Debit air mengalir ke dalam keramba $\left(\mathrm{m}^{3}\right)$

$\mathrm{O}_{\text {in }}=$ Kadar oksigen air bebas $(\mathrm{mg} / \mathrm{L})$

$\mathrm{O}_{\text {out }}=$ Kadar oksigen minimal kebutuhan ikan $(\mathrm{mg} / \mathrm{L})$

Daya Dukung Perairan

$$
=\frac{\mathrm{X} \mathrm{Kg} \mathrm{O}_{2}}{\text { Laju Konsumsi Ikan (mg/kg/jam) }}
$$

Daya Dukung Kawasan Budidaya

$=$ Luas Potensi Lahan $\mathrm{x}$ Kedalaman Air Daya Dukung Perairan

\section{HASIL DAN PEMBAHASAN}

\section{Potensi Lahan Pengembangan Budidaya}

Mengacu kepada hasil kajian Badan Penelitian dan Pengembangan Pengelolaan Sumberdaya Perairan dan Lingkungan (BPP-PSPL) Universitas Riau, diketahui bahwa luas perairan di KKPD Datok Bandar yang berpotensi dikembangkan untuk pemanfaatan budidaya sebesar 3.736,01 ha, sebagaimana terdapat dalam Tabel 1.

Tabel 1. Potensi Pengembangan Budidaya Perikanan di Wilayah KKPD Datok Bandar

\begin{tabular}{llcc}
\hline No & $\begin{array}{c}\text { Lokasi / De- } \\
\text { sa }\end{array}$ & $\begin{array}{c}\text { Potensi } \\
\text { Lahan yang } \\
\text { Sesuai (Ha) }\end{array}$ & $\begin{array}{c}\text { Luas Lahan } \\
\text { yang boleh di- } \\
\text { manfaatkan } \\
\text { (Ha) }\end{array}$ \\
\hline 1 & Benan & $1.591,42$ & 795,71 \\
2 & Limbung & 114,58 & 57,29 \\
3 & Mamut & 583,78 & 291,89 \\
4 & Penaah & 440,69 & 220,345 \\
5 & Tajur Biru & 321,35 & 160,675 \\
6 & Sekanah & 362,84 & 181,42 \\
7 & Batu Be- & 321,25 & 160,675 \\
& lubang & & \\
\hline \multicolumn{2}{c}{ Jumlah } & $3.736,01$ & $1.868,005$ \\
\hline
\end{tabular}

Sumber: BPP-PSPL UR

Luas lahan yang dapat dimanfaatkan untuk usaha budidaya di dalam Karamba Jaring Tancap (KJT), Karamba Jaring Apung (KJA) maupun rumput laut adalah sebesar $1.868,005 \mathrm{Ha}$, atau sekitar 50\% dari seluruh potensi yang ada. Penetapan nilai potensi ini dilakukan dengan mempertimbangkan kemampuan lingkungan untuk me-recovery limbah budidaya yang tersuspensi saat kegiatan budidaya berlangsung.

Adapun potensi lahan yang sesuai untuk kegiatan budidaya adalah sebesar 3.736,01 ha. Namun agar kegiatan budidaya dapat berkelanjutan maka berdasarkan hasil perhitungan daya dukung kawasan, luas wilayah perairan yang dapat dimanfaatkan untuk kegiatan budidaya adalah sebesar 268,420 ha. Sedangkan lokasi budidaya, baik KJA, KJT, brumput laut, dan teripang di wilayah perairan pada masingmasing desa, terdapat pada Gambar 2.

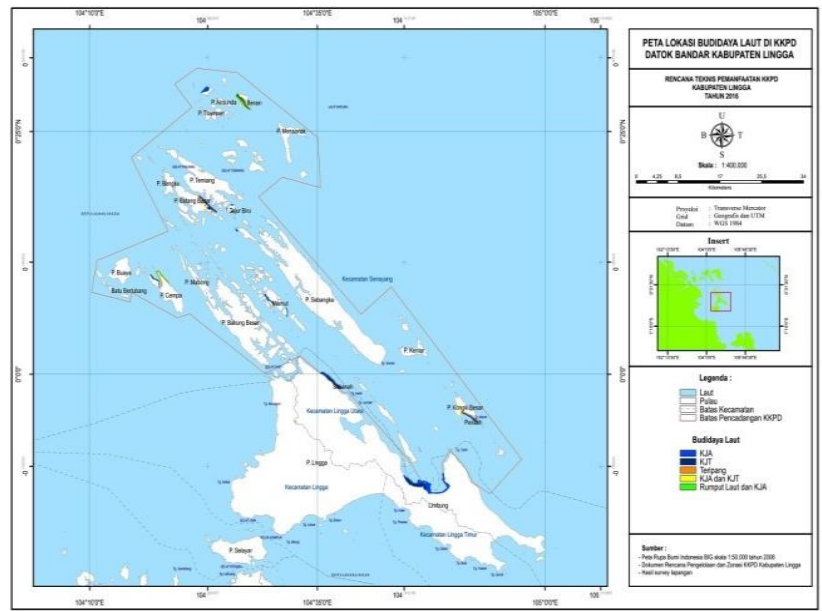

Gambar 2. Peta Lokasi Budidaya di Wilayah KKPD Datok Bandar Kabupaten Lingga

Hasil penelitian juga merumuskan jumlah unit usaha budidaya yang dapat dibangun di wilayah KKPD Datok Bandar Kabupaten Lingga sebagaimana terdapat dalam Tabel 2. Pengembangan usaha dilakukan dengan membuat keramba yang dibangun secara berbanjar 2 (dua) dan vertikal ke arah laut. Hal ini dilakukan agar sirkulasi air menjadi lancar sehingga tidak mencemari perairan. Disamping itu, proses sortasi dan penggantian keramba dilakukan setiap bulan sebagai upaya pencegahan penyakit yang dapat merusak lingkungan.

Tabel 2. Jumlah Unit Usaha Budidaya di Wiayah

\begin{tabular}{|c|c|c|c|c|c|}
\hline \multirow[b]{2}{*}{ No } & \multirow[b]{2}{*}{ Lokasi } & \multirow{2}{*}{$\begin{array}{c}\text { Daya } \\
\text { Dukung } \\
\text { Kawasan } \\
\text { Budidaya } \\
\text { (Ha) }\end{array}$} & \multicolumn{3}{|c|}{ Jumlah Unit Usaha } \\
\hline & & & $\begin{array}{l}\text { Petak } \\
\text { /Unit }\end{array}$ & $\begin{array}{c}\text { Usaha } \\
\text { Kecil }\end{array}$ & $\begin{array}{c}\text { Usaha } \\
\text { Menengah }\end{array}$ \\
\hline 1 & nan & 114,338 & 7.146 & 4.288 & 2.858 \\
\hline 2 & mbung & 8,232 & 515 & 309 & 206 \\
\hline & amut & 41,943 & 2.621 & 1.573 & 1.049 \\
\hline & naah & 31,662 & 1.979 & 1.187 & 792 \\
\hline & juur Biru & 23,088 & 1.443 & 866 & 577 \\
\hline & kanah & 26,069 & 1.629 & 978 & 652 \\
\hline 7 & tu Belubang & 23,081 & 1.443 & 866 & 577 \\
\hline & Jumlah & 268,420 & 16.776 & 10.066 & 6.710 \\
\hline
\end{tabular}
KKPD Datok Bandar Lingga

\section{Daya Dukung Kawasan Pengembangan Budidaya}

Perhitungan daya dukung untuk kegiatan budidaya pada wilayah KKPD Datok Bandar dilakukan dengan menggunakan pendekatan asimilasi oksigen terlarut. Berdasarkan hasil perhitungan tersebut, daya dukung kawasan untuk menunjang kegiatan pengembangan usaha budidaya di wilayah ini hanya sebesar $7.2 \%$ dari seluruh potensi yang ada (Tabel 3). Perhitungan daya dukung kawasan dilakukan untuk mendukung pengembangan kegiatan budidaya di wilayah KKPD namun dengan tetap menjaga ekosistem yang ada. 
Tabel 3. Daya Dukung Kawasan Pengembangan Budidaya di KKPD Datok Bandar Kab. Lingga Berdasarkan Perhitungan Asimilasi Oksigen Terlarut.

\begin{tabular}{llcc}
\hline No & $\begin{array}{c}\text { Lokasi / } \\
\text { Desa }\end{array}$ & $\begin{array}{c}\text { Potensi Lahan } \\
\text { yang Sesuai } \\
\text { (Ha) }\end{array}$ & $\begin{array}{c}\text { Daya Dukung } \\
\text { Kawan Budidaya } \\
\text { (Ha) }\end{array}$ \\
\hline 1 & Benan & $1.591,42$ & 114,338 \\
2 & Limbung & 114,58 & 8,232 \\
3 & Mamut & 583,78 & 41,943 \\
4 & Penaah & 440,69 & 31,662 \\
5 & Tajur Biru & 321,35 & 23,088 \\
6 & Sekanah & 362,84 & 26,069 \\
7 & Batu Be- & 321,25 & 23,081 \\
& lubang & & \\
\hline \multicolumn{2}{c}{ Jumlah } & $3.736,01$ & 268,420 \\
\hline
\end{tabular}

Berdasarkan hasil perhitungan Daya Dukung Kawasan pada Tabel 3 , dan perkiraan perhitungan luas petak/unit tambak yang akan dikelola di wilayah KKPD Datok Bandar sebesar $16 \mathrm{~m}^{2}$, maka jumlah petak atau unit usaha budidaya yang diperbolehkan di wilayah KKPD Datok Bandar Kabupaten Lingga adalah sebanyak 16.776 petak/unit. Jumlah ini diperuntukkan bagi 2 kelompok pelaku usaha, yaitu usaha kecil dan menengah, dengan alokasi sebesar $60 \%$ petak/unit untuk usaha kecil dan $40 \%$ untuk usaha menengah dari luasan wilayah KKPD Datok Bandar yang bisa digunakan, sebagaimana tersaji pada Tabel 2. Pemberdayaan masyarakat dengan memberikan alokasi cukup besar pada pembudidaya skala kecil dan menengah diharapkan dapat meningkatkan kesejahteraan masyarakat setempat (Purnomo et. al., 2013; Romadhon, 2014).

Dari hasil kajian daya dukung kawasan menggunakan perhitungan asimilasi oksigen terlarut sebagaimana tersaji pada Tabel 3, luas potensi lahan perairan yang dapat dimanfatkan untuk kegiatan budidaya adalah sebesar $7.2 \%$ dari seluruh wilayah yang tersedia. Hal ini dilakukan agar wilayah di Kawasan Konservasi Perairan Daerah Datok Bandar Kabupaten Lingga dapat terus mendukung kegiatan budidaya secara berkelanjutan. Salah satu cara agar ekologi yang ada tetap terjaga kelestariannya adalah dengan menjaga agar daya dukung kawasan dapat menampung jumlah ikan pada suatu lingkungan perairan untuk dapat memenuhi kebutuhan populasi ikan tanpa menurunkan kualitas perairan (Novita et. al., 2015).

Hasil senada juga terdapat dalam penelitian Prasita et al., (2008) yang menunjukkan bahwa pemanfataan lahan perairan yang melampaui daya dukung lingkungannya menyebabkan peningkatan teknologi budidaya ke semi-intensif atau intensif tidak dimungkinkan untuk dilakukan. Oleh karenanya, meskipun hasil kajian Badan Penelitian dan Pengembangan Pengelolaan Sumberdaya Perairan dan Lingkungan (BPPPSPL) Universitas Riau menyatakan bahwa luas lahan yang dapat dimanfatkan adalah sebesar 1.868,005 ha, namun berdasarkan hasil pengukuran daya dukung kawasan, hanya 268,240 ha yang dapat dimanfaatakan untuk pengembangan budidaya, agar kegiatan budidaya dan konservasi dapat sejalan serta berkelanjutan.

\section{Parameter Kualitas Air}

Hasil pengukuran secara umum menunjukkan bahwa kondisi perairan di wilayah KKPD Datok Bandar Kabupaten Lingga masih dapat digunakan untuk kegiatan budidaya. Hasil pengamatan parameter kualitas air di KKPD Datok Bandar Kabupaten Lingga disajikan pada Tabel 4.

Tabel 4. Parameter Kualitas Air di Wilayah KKPD Datok Bandar Kabupaten Lingga

\begin{tabular}{|c|c|c|c|c|c|c|c|}
\hline \multirow[b]{2}{*}{ Parameter } & \multicolumn{7}{|c|}{ Lokasi Pengembangan Budidaya } \\
\hline & 苂 & 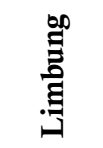 & 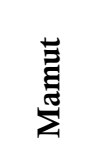 & 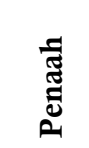 & 莺. & 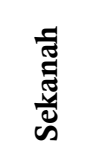 & हू \\
\hline Salinitas & 32 & 33 & 33 & 32 & 32 & 33 & 33 \\
\hline Suhu $\left({ }^{\circ} \mathrm{C}\right)$ & 29.8 & 29.1 & 30.5 & 30.6 & 30 & 29.7 & 30.1 \\
\hline $\begin{array}{l}\text { Kecerahan } \\
(\%)\end{array}$ & 100 & 100 & 100 & 100 & 100 & 100 & 100 \\
\hline $\mathrm{pH}$ & 8.3 & 7.5 & 7 & 7 & 8.6 & 8.3 & 7.15 \\
\hline $\mathrm{DO}(\mathrm{mg} / \mathrm{L})$ & 5.6 & 6,0 & 5,8 & 6,1 & 6,1 & 6,2 & 6.7 \\
\hline $\begin{array}{l}\text { Arus }(\mathrm{m} / \mathrm{s}) \\
\text { Tinggi }\end{array}$ & 0.5 & 0.4 & 0.3 & 0.7 & 0.4 & 0.8 & 1 \\
\hline $\begin{array}{l}\text { Gelombang } \\
\text { (m) }\end{array}$ & 3 & 5 & 2 & 4 & 2 & 5 & 6 \\
\hline $\begin{array}{l}\text { Kedalaman } \\
(\mathrm{m})\end{array}$ & 4 & 3 & 5 & 4 & 4 & 6 & 4 \\
\hline $\begin{array}{l}\mathrm{BOD} \\
(\mathrm{mg} / \mathrm{L})\end{array}$ & 6 & 6,0 & 5,9 & 6 & 6,1 & 5,8 & 6,0 \\
\hline $\begin{array}{l}\text { Nitrat } \\
(\mathrm{mg} / \mathrm{L})\end{array}$ & 0,002 & 0,002 & 0,002 & 0,002 & 0,002 & 0,002 & 0,002 \\
\hline $\begin{array}{l}\text { Nitrit } \\
(\mathrm{mg} / \mathrm{L})\end{array}$ & 0,02 & 0,03 & 3 & 0,02 & 0,02 & 0,03 & 0,03 \\
\hline $\begin{array}{l}\text { Pospat } \\
\text { (mg/L) }\end{array}$ & 0,09 & 0,06 & 0,06 & 0,07 & 0,06 & 0,07 & 0,08 \\
\hline $\begin{array}{l}\text { Klorofil-a } \\
\text { (mg/L) }\end{array}$ & 5,57 & 4,12 & 4,05 & 6,39 & 4,59 & 4,18 & 4,83 \\
\hline
\end{tabular}

Penggunaan analisa daya dukung kawasan dengan menggunakan perhitungan asimilasi oksigen terlarut, dilakukan karena menurut Djamhur et. al., (2019) kapasitas asimilisasi pada suatu penelitian dapat digunakan untuk mengetahui seberapa besar perairan yang ada mampu menerima beban masukan senyawa, sehingga tidak menurunkan fungsi ekologi perairan. Oleh karenanya penentuan daya dukung perairan juga dilakukan dengan memperhatikan unsur bahan pencemar yang ada di wilayah tersebut (Novita et. al., 2015) sebagaimana yang terdapat dalam Tabel 4.

Dampak negatif dari peningkatan nutrient di perairan dapat dicegah dengan membatasi jumlah nutrient yang masuk ke perairan dengan membatasi jumlah keramba yang dibangun (Novita et. al., 2015). Pembatasan jumlah keramba di wilayah KKPD Daotk Bandar kabupaten Lingga juga harus dilakukan agar ketersediaan oksigen terlarut dalam perairan dapat terus menunjang kegiatan budidaya di wilayah tersebut (Mansur et. al., 2013). Oleh karenanya, jumlah 
unit/petak keramba yang direkomendasikan di wilayah KKPD Datok Bandar adalah sebanyak 16.776 unit, dengan luas masing-masing tambak sebesar 16 $\mathrm{m}^{2}$. Pembagian alokasi petak/unit di wilayah ini sebesar $60 \%$ untuk usaha kecil dan $40 \%$ untuk usaha menengah dilakukan untuk memberi kemanfaatan bagi masyarakat sekitar dengan adanya kawasan konservasi (Firdaus \& Sari, 2010). Jumlah KJT dan KJA yang dibangun juga harus sesuai dengan jumlah kuota sebagaimana yang terdapat dalam Tabel 5. Disamping itu, proses sortasi dan penggantian keramba dilakukan setiap bulan sebagai upaya pencegahan penyakit yang dapat merusak lingkungan.

Berdasarkan hasil pengukuran kualitas air, wilayah KKPD Datok Bandar dapat dibagi menjadi 3 peruntukkan kegiatan yakni Daerah yang dapat dimanfaatkan untuk pengembangan rumput laut, yaitu perairan Desa Benan, Desa Penaah, Desa Sekanah, Desa Tajur Biru, Desa Mamut, Desa Batu Belubang dan Desa Limbung. Daerah yang dapat digunakan untuk pengembangan usaha keramba jaring apung, yaitu perairan Desa Tajur Biru dan Desa Mamut. Daerah yang dapat digunakan untuk pengembangan usaha Budidaya Keramba jarring Tancap, yaitu perairan Desa Benan, Dsa Penaah, Desa Sekanah, Desa Tajur Biru, Desa Mamut, Desa Batu Belubang dan Desa Limbung.

Pengembangan usaha budidaya juga harus memperhatikan kualitas air di wilayah tersebut serta ikanikan yang terdapat di wilayah perairan KKPD Datok Bandar. Berdasarkan hasil pengukuran kualitas air dan kearifan lokal masyarakat, hampir semua jenis komoditas perikanan, terutama jenis ikan karang, dapat dikembangkan menjadi unggulan usaha budidaya di wilayah KKPD Datok Bandar Kabupaten Lingga sepanjang komoditas tersebut telah memenuhi ketentuan yang disyaratkan dalam pemilihan bibit. Pemilihan ikan-ikan unggulan ini dikarenakan nilai ekonomi ikan, ketersediaan benih di alam, dan pengetahuan lokal masyarakat terhadap pemeliharaan ikanikan tersebut. Pemahaman terhadap pengetahuan lokal masyarakat terhadap kondisi ekologis merupakan salah satu bentuk strategi konservasi di wilayah KKPD (Kennedy et al., 2019). Adapun jenis ikan-ikan unggulan tersebut antara lain Ikan Kerapu Sunu (Plectropomus leopardus), Ikan Kerapu Macan (Epinephelus fuscoguttatus), Ikan Kakap Merah (Utjanus campechanus), Ikan Kerapu Lumpur (Epinephelus tauvina), Ikan Bawal Bintang (Pompanoo Silver), Teripang dan Kuda Laut (Hippocampus).

Beberapa hal yang harus diperhatikan pada pengembangan usaha budidaya untuk menjaga kelestarian ikan dan keseimbangan ekosistem di wilayah KKPD Datok Bandar Kabupaten Lingga, diantaranya; 1) Asal bibit diutamakan menggunakan Benih ikan yang berasal dari kegiatan pembenihan (hatchery), dengan ketentuan Non Genetic Modification Organism (GMO). Mahrus (2014) menyimpulkan bahwa hasil biota rekayasa atau GMO memiliki efek bagi kesehatan masyarakat. Bawa \& Anilakumar (2013) menyimpulkan bahwa GMO dapat menghasilkan efek turunan lain bagi ekosistem, terutama terjadinya transgenic (perubahan genetik) organisme lain yang memiliki asosiasi dengan GMO. 2) Penggunakan obatobatan yang tidak mengandung residu atau ramah lingkungan, baik untuk meningkatkan ketahanan tubuh maupun untuk mengobati benih yang sakit. Sebagaimana diketahui bahwa penggunaan prebiotic pada ikan budidaya sangat berdampak pada konsumsi manusia. Prebiotik pada ikan mengandung komponen antibiotik, manusia yang mengkonsumsi ikan dengan antibotik tinggi menyebabkan resistensi terhadap antibiotik (Humaida, 2014; Pratiwi, 2017). 3) Penangkapan yang ramah lingkungan dengan mempertimbangkan kemampuan rekruitmen alami ikan serta ukuran yang digunakan harus di atas 100 gr, karena jika di bawah 100 gr pada umumnya masih bersifat koloni sehingga kemungkinan punah di alam akan semakin tinggi. Hal lain yang juga harus diperhatikan adalah densitas benih di daerah konservasi maksimal 30 $\mathrm{ekor} / \mathrm{m}^{2}$. Pemanfaatan ikan harus dilakukan secara konservatif dengan tetap memperhatikan pemanfaatan yang ramah lingkungan. 4) Jenis pakan yang diperbolehkan adalah pelet buatan yang mudah terurai serta tidak mengandung unsur perangsang tumbuh yang berlebihan (10\%). Pemberian pakan pellet kepada organisme budidaya juga tidak melebihi $5 \%$ dari berat tubuh ikan per harinya. Pemberian makan rucah hanya dilakukan dalam keadaan spesifik, seperti tahap adaptasi benih alam, ketersediaan pelet yang tidak ada akibat cuaca dan transportasi. Pemberian benih alam hanya diperbolehkan maksimal $7 \%$ dari berat tubuh ikan per harinya. Penelitian Yulfiperius et al. (2018) menyatakan bahwa pakan ikan dari bahan organik sangat cocok untuk mengurangi beban pencemaran lingkungan. Limbah organik rumah tangga dapat dikembangkan menjadi pellet ikan ramah lingkungan (Burhanuddin et al. 2021).

Dari beberapa poin diatas, maka dapat disimpulkan bahwa kegiatan budidaya harus menggunakan benih Spesifik Patogen Free (SPF) atau benih bebas penyakit dari hasil produksi pembenihan yang bersertifiasi sehingga penggunaan obat-obatan dapat dikurangi seminimal mungkin, Menggunakan obat-obatan yang ramah ligkungan agar tidak menimbulkan residu yang membahayakan lingkungan, Menggunakan bahan pakan komersil yang mudah terurai serta mampu memicu pertumbuhan dengan Food Convertion Rate (FCR) dan Menggunakan benih ikan non Genetic Modification Organism (GMO) agar tidak beresiko pada saat terjadi lepas di alam.

\section{Teknologi Budidaya}

Penggunaan teknologi dalam usaha budidaya di wilayah KKPD Datok Bandar Kabupaten Lingga juga perlu mendapat perhatian demi kelangsungan dan kelestarian ekosistem yang ada. Penggunaan teknologi yang tidak tepat dapat menyebabkan kerusakan pada wilayah konservasi. Oleh karenanya, teknologi yang dapat digunakan untuk pengembangan budidaya di wilayah ini harus memperhatikan berbagai hal seperti Menggunakan bahan konstruksi keramba jarring 
apung (KJA) maupun keramba jarring tancap (KJT) yang ramah lingkungan, Menerapkan bioteknologi yang ramah lingkungan sehingga dapat memicu pertumbuhan dan tidak menimbulkan efek negatif pada lingkungan.

Konstruksi media budidaya di wilayah KKPD Datok Bandar Kabupaten terbagi menjadi 5 (lima), yaitu (1) kerambah jarring tancap beton, (2) Kerambah jarring tancap kayu, (3) Keramba jarring apung, (4) Budidaya rumput laut (Long Line Tancap), dan Budidaya rumput laut (Long Line Apung).

\section{Keramba Jaring Tancap Beton dan Kayu}

Spesifikasi konstruksi dari keramba jaring tancap (Gambar 3) beton dan kayu yang direkomendasikan untuk dapat digunakan di wilayah KKDPD Datok Bandar Kabupaten Lingga dengan spesifikasi tiang panjang berjumlah 4 tiang untuk satu (1) petak pertama, dan hanya butuh penambahan 1 petak berikutnya dalam sekali pembangunan, sehingga untuk 2 petak hanya diperlukan 6 tiang pancang. Ukuran tiang $400 \mathrm{~cm} \times 50 \mathrm{~cm} \times 50 \mathrm{~cm}$.

Bahan terbuat dari beton bertulang khusus bangunan laut, Formasi yang disarankan adalah dua petak berbaris sehingga sirkulasi air dalam keramba tidak terhambat, Tempat berjalan di atas tonggak terbuat dari beton bertulang untuk bangunan laut setebal
$12 \mathrm{~cm}$ dengan ukuran bingkai luar $50 \mathrm{~cm}$ dan bingkai dalam $40 \mathrm{~cm}$, Jarring keramba terbuat dari bahan polyethylene dengan ukuran $300 \mathrm{~cm}$ x $400 \mathrm{~cm}$ x $400 \mathrm{~cm}$ dan Dengan jarak $1 \mathrm{~m}$ dari dasar perairan maka surut terendah harus minimal setinggi $2 \mathrm{~m}$, sehingga menyisakan ruang $1 \mathrm{~m}$ bagian jarring yang terendam air. Dengan jarak $1 \mathrm{~m}$ dari dasar perairan maka pasang tertinggi harus maksimal setinggi 3,5 m sehingga menyisakan ruang $0,5 \mathrm{~m}$ bagian jarring yang tidak terendam air (Gambar 3.a dan Gambar 3.b).

Sedangkan spesifikasi untuk keramba jarring tancap kayu (Gambar 3.c) yang direkomendasikan untuk dapat digunakan di wilayah ini dengan spesifikasi agar tahan pada daerah yang berombak dan gelombang kuat, menggunakan bahan tonggak dan alas untuk berjalan dari kayu khusus yang memiliki kekuatan dan ketahanan untuk bangunan laut seperti kayu ulin atau kayu lain yang sudah diberi prlakuan khusus untuk tahan air laut dan gelombang. Tiang pancang berjumlah 24 tiang untuk 1 petak. Hal ini mengingat keramba merupakan bangunan laut yang harus tahan akan gelombang dan ombak, maka banyaknya tiang pancang sebagai penopang struktur bangunan sangat penting. Penambahan petak berikutnya hanya memerlukan 14 tiang pancang tambahan.

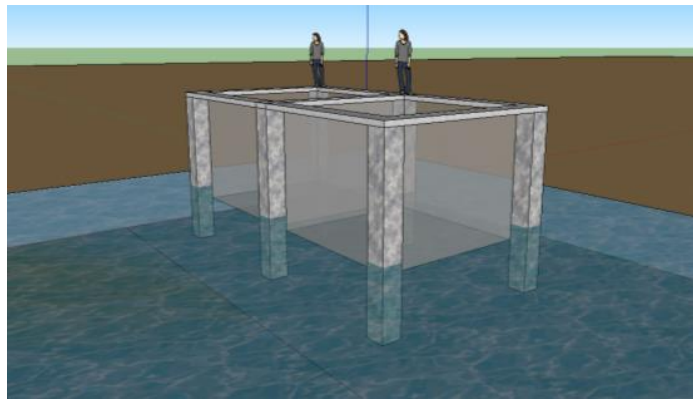

(a)

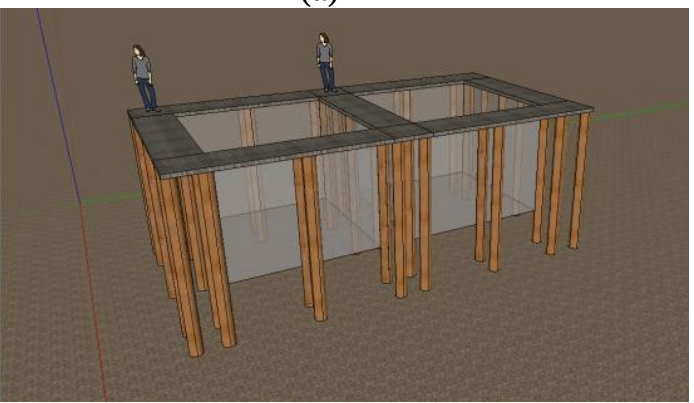

(c)

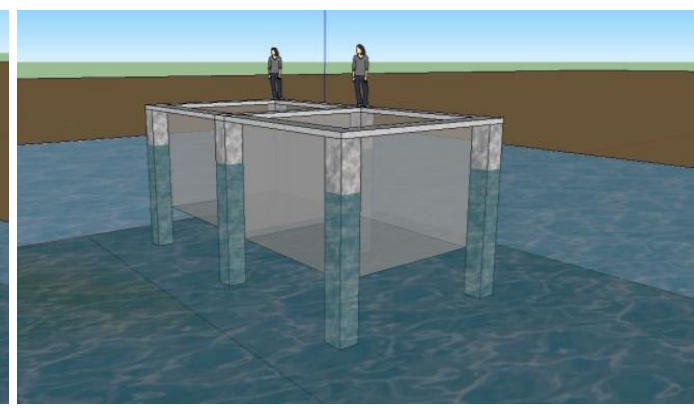

(b)

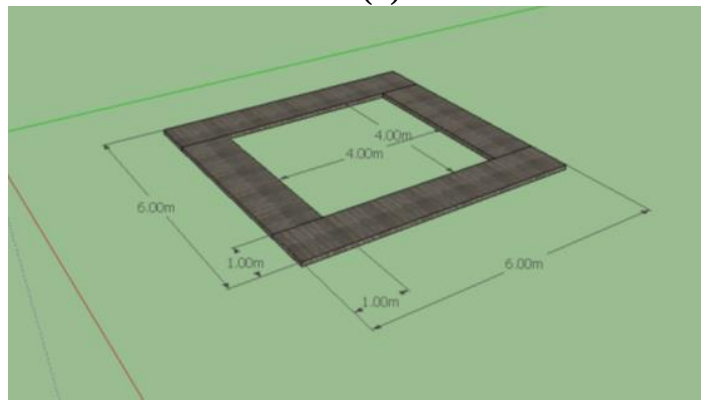

(d)

Gambar 3. Spesifikasi konstruksi dari keramba jaring tancap; a) Jaring tancap beton pada air surut, b) Jaring tancap beton pada air pasang, c) Jaring tancap kayu, d) Tempat berjalan di atas keramba.

Ukuran tiang pancang di atas tanah $400 \mathrm{~cm}$, sedangkan ukuran panjang ke dalam tanah tergantung kedalaman yang mencapai kestabilan atau kekokohan pada tiang, dengan diameter tiang $20 \mathrm{~cm}$. Tempat berjalan di atas tinggak terbuat dari beton bertulang untuk bangunan laut, setebal $10 \mathrm{~cm}$ dengan ukuran bingkai luar $600 \mathrm{~cm}$ dan bingkai dalam $400 \mathrm{~cm}$ (Gambar 3.d).

\section{Keramba Jaring Apung}

Jarring keramba terbuat dari bahan polyethylene dengan ukuran $300 \mathrm{~cm}$ x $400 \mathrm{~cm}$ dan $400 \mathrm{~cm}$. Tiang pancang berjumlah 24 tiang untuk 1 petak pertama, dan hanya butuh penambahan 1 petak berikutnya, sehingga untuk 2 petak hanya diperlukan 14 tiang pancang. Formasi yang disarankan adalah dua petak ber- 
baris. Dengan jarak $1 \mathrm{~m}$ dari dasar perairan maka surut terendah harus minimal setinggi $1.5 \mathrm{~m}$, sehingga menyisakan ruang $0.5 \mathrm{~m}$ bagian jarring yang terendam air. Dengan jarak $1 \mathrm{~m}$ dari dasar perairan maka pasang tertinggi harus maksimal setinggi $3.5 \mathrm{~m}$ sehingga menyisakan ruang $0.5 \mathrm{~m}$ bagian jarring yang tidak terendam air.

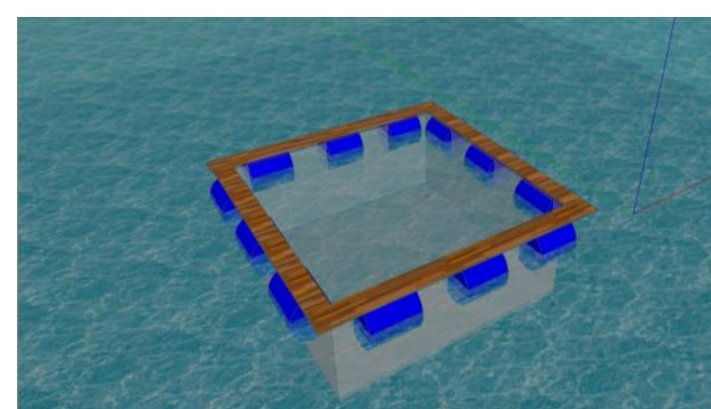

(a)

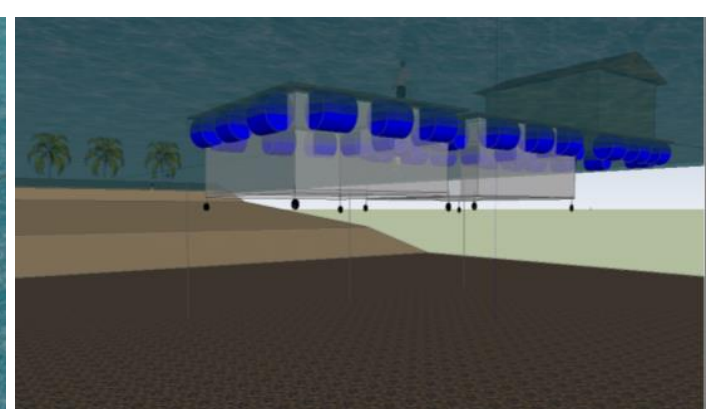

(b)

Gambar 4. Konstruksi Keramba Jaring Apung; a) Keramba jaring apung tampak dari permukaan perairan,

b) Keramba jaring apung tampak dari dasar perairan

Adapun konstruksi keramba jaring apung yang dapat digunakan di wilayah KKPD Datok Bandar Kabupaten Lingga adalah Keramba jarring apung menggunakan bahan yang memiliki kekuatan dan ketahanan untuk bangunan laut seperti kayu ulin atau kayu yang sudah diberi perlakuan khusus untuk tahan air laut dan gelombang. Pelampung berupa drum fiber dengan volume 200 liter atau menyesuaikan, sehingga hanya memiliki daya apung maksimal untuk beban $180 \mathrm{~kg}$. Untuk keramba setidaknya hanya setengah pelampung yang terendam sehingga 12 pelampung akan dapat menahan beban sebesar $1080 \mathrm{~kg}$ (Gambar 4.a).

Tempat berjalan di atas pelampung terbuat dari beton bertulang untuk bangunan laut, setebal $10 \mathrm{~cm}$ dengan ukuran bingkai luar $700 \mathrm{~cm}$ dan bingkai dalam $600 \mathrm{~cm}$. lebar untuk brjalan $50 \mathrm{~cm}$. Jaring terbuat dari bahan polyethylene dengan ukuran $300 \mathrm{~cm}$ x $600 \mathrm{~cm}$ dan $600 \mathrm{~cm}$ (menyesuaikan). Setiap jaring perlu dipasang pemberat pada sudut bagian bawahnya, di- mana akan terdapat 4 pemberat dengan berat yang disesuaikan agar jarring dalam kondisi tegang saat diterpa ombak dan arus.

Sarana tambahan berupa rumah jaga dengan ukuran yang sama dengan satu petak keramba. Untuk sarana tambahan banyaknya pelampung harus di tambah disesuaikan dengan beban yang akan diletakkan seperti konstruksi bangunan rumah jaga, perkakas, pekerja yang akan menghuninya, dan barang yang akan disimpan di dalamnya (Gambar 4.b).

\section{Budidaya Rumput Laut dengan Metode Long line}

Konstruksi budidaya rumput laut dapat menggunakan long line tancap dan long line apung. Untuk long line tancap budidya rumput laut, konstruksi yang direkomendasikan adalah Long line menggunakan tonggak sebagai tiang pancang talinya dengan bahan kayu ataupun beton (Gambar 5).

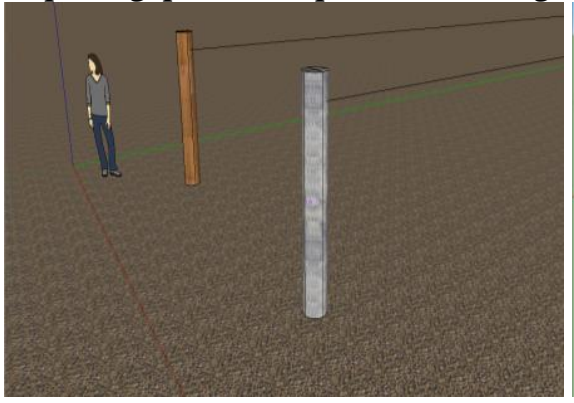

(a)

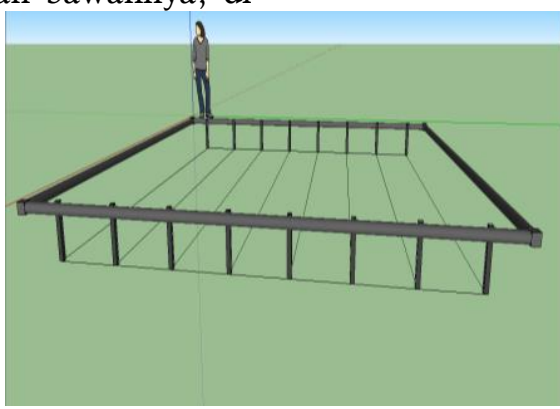

(b)

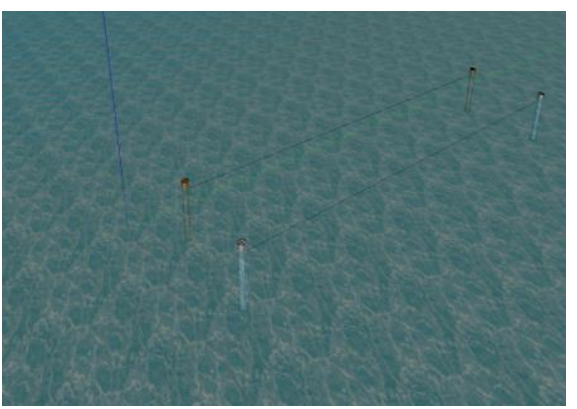

(c)

Gambar 5. Konstruksi Long line untuk budidaya rumput laut; a) Konstruksi tiang pancang, b) Desain long line apung, c) Posisi Tali long line pada saat surut

Jarak antar tiang $20 \mathrm{~m}$ dengan toleransi tali terhadap pasang surut adalah $2 \mathrm{~m}$, sehingga panjang tali $22 \mathrm{~m}$. Penambahan pelampung pada tali disesuaikan dengan banyaknya rumput laut yang diletakkan agar tali tetap berada pada kedalaman yang diinginkan. Diameter tiang $30 \mathrm{~cm}$ dengan tinggi permukaan di atas tiang substrat adalah $2 \mathrm{~m}$. Ukuran panjang tiang ke dalam tanah disesuaikan hinga kedalaman yang membuat tiang stabil/kokoh.

Jarak antar tiang yang aman adalah $4 \mathrm{~m}$. Ini untuk mencegah tali dari tiang yang lain saling terbelit ssat terkena arus dan gelombang. Posisi tali masih dalam keadaaan terendam pada saat surut dan masih pada posisi kedalaman yang diinginkan jika saat pasang tertinggi (Gambar 5.a). Peletakkan long line di daerah 
Tengku Said Razai, Fitria Ulfah, Febrianti Lestari, Dony Apdillah, Ita Karlina, Fadliyah Idris,

Try Febrianto | DLI 8 (2) (2021) 129-137 137

pesisir harus memperhatikan selisih ketinggian air saat pasang dan surut dimana jika panjang toleransi tali 2 $\mathrm{m}$, maka selisih pasang dan surut maksimal adalah 0,5 m. Hal ini untuk memastikan tali agar tetap terendam $0, .5 \mathrm{~m}$ di bawah permukaan air laut.

Sedangkan untuk long line apung untuk budidaya rumput laut, konstruksi yang direkomendasikan di wilayah KKPD Datok Bandar Kabupaten Lingga adalah Long line apung untuk rumput laut menggunakan pipa PVC 4 inci berbentuk persegi panjang dengan panjang setiap rusuk $6 \mathrm{~m}$. Dengan daya apung maksimal $56.52 \mathrm{~kg}$ maka beban maksimal yang dapat diberikan adalah $56.25 \mathrm{~kg}$, dimana beban tersebut berupa tali, penahan tali dan rumput laut itu sendiri (Gambar 5.b).

Untuk rumput laut beban maksimal saat mencapai panen adalah $56 \mathrm{~kg}$, dimana setiap tali yang panjangnya $6 \mathrm{~m}$ dapat menopang rumput laut sampai panen dengan bobot setiap talinya $7 \mathrm{~kg}$. Pada Long Line Apung ini dapat diletakkan 8 tali/line dengan jarak antar tali $75 \mathrm{~cm}$ agar rumput laut mendapatkan sirkulasi air dan nutrisi sehingga dapat tumbuh dengan baik. Panjang penahan tali/line sepanjang $50 \mathrm{~cm}$ kea rah bawah agar rumput laut selalu terendam di bawah permukaan air dan tetap mendapatkan sinar matahari untuk pertumbuhannya. Posisi long line apung di perairan akan selalu mengapung pada posisi kedalaman yang konstan dan tidak berubah pada saat pasang dan surut (Gambar 5.c). Disarankan sesama long line apung untuk disatukan dengan tali dan setiap long line apung diberi jangkar agar tidak terbawa arus.

\section{SIMPULAN}

Berdasarkan hasil kajian di wilayah KKPD Datok Bandar Kabupaten Lingga, pembatasan luas lahan dan jumlah unit usaha budidaya di kawasan konservasi merupakan hal penting. Hal ini dilakukan untuk memastikan keberlanjutan pengelolaan di masa yang akan datang. Implikasi dari hasil penelitian ini dapat digunakan sebagai dasar penerbitan izin pemanfaatan KKPD untuk kegiatan pengembangan usaha budidaya, disamping untuk memastikan kelompok pembudidaya dengan skala usaha kecil dan menengah memiliki proporsi yang besar di wilayah konservasi. Selain untuk memastikan eksistensi masyarakat lokal yang umumnya pembudidaya kecil, kawasan konservasi sangat rentan terhadap perubahan lingkungan, sehingga faktor resiko dan dampak dari pemanfaaatan usaha penting untuk dipertimbangkan.

\section{UCAPAN TERIMAKASIH}

Ucapan terima kasih kepada Dinas Kelautan dan Perikanan Kabupaten Lingga atas pembiayan kegiatan ini, juga kepada responden, informan, dan masyarakat di wilayah KKPD Datok Bandar Kabupaten Lingga.

\section{DAFTAR PUSTAKA}

Affan, J.M. (2012). Identifikasi Lokasi untuk Pengembangan Budidaya Keramba Jaring Apung (KJA) Berdasarkan Faktor Lingkungan dan Kualitas Air di Perairan Pantai Timur Bangka Tengah. Depik Jurnal Ilmu-ilmu Perairan, Pesisir dan Perikanan, 1(1): 78-85. https://doi.org/10.13170/depik.1.1.30

Alifatri, L.O., Hariyadi, S.H., \& Susanto, A. (2017). Analisis Daya Dukung Lahan untuk Pengembangan Budi Daya Kerapu di Perairan Tambak Kecamatan Cilebar, Kabupaten Karawang. Jurnal Ilmu Pertanian Indonesia (JIPI), 22(1): 52-66. https://doi.org/10.18343/jipi.22.1.52

Bato, M., Yulianda, F., \& Fachruddin, A. (2013). Kajian Manfaat Kawasan Konservasi Perairan Bagi Pengembangan Ekowisata Bahari: Studi Kasus di Kawasan Konservasi Perairan Nusa Penida, Bali. Depik Jurnal Ilmu-ilmu Perairan, Pesisir dan Perikanan, 2(2): 104-113. https://doi.org/10.13170/depik.2.2.777.

Bawa. A.S., \& Anilakumar, K.R. (2013). Genetically modified foods: safety, risks and public concerns-a review. Journal Food Science Technology 50 (6) : 1035-1046. DOI 10.1007/s13197-012-0899-1.

Burhanuddin., Khaeriyah A., Akmaluddin., Arwati. S., Ikbal. M., Anwar, A,. \& Hamsah. (2021). Meningkatkan Pemahamanan Pembuatan Pakan Ikan Pada Anggota Kelompok Nelayan Jenber di Kelurahan Tanjung Merdeka, Kota Makassar. To Maega | Jurnal Pengabdian Masyarakat 4 (1) : 2634.

Djamhur, M., Boer, M., Bengen, D.G., \& Fahrudin, A. (2019). Prosiding Seminar Nasional Kelautan dan Perikanan 2019. Fakultas Perikanan dan Ilmu Kelautan Unpatti, Ambon, pp. 259-267. https://doi.org/10.30598/semnaskp-26

Firdaus, M., \& Sari, Y.D. (2010). Pemanfataan dan Pengelolaan Kawasan Konservasi Sumberdaya Perikanan (Studi Kasus di Lubuk Larangan Lubuk Panjang Barun-barung Balantai, Kabupaten Pesisir Selatan, Sumatera Barat). Jurnal Bijak dan Riset Sosial KP, 5(1): 1-18. http://dx.doi.org/10.15578/jsekp.v5i1.5788

Hakim, A., Setiono, Ningtias, P. Tasrif, K., Sudarsono, Ari S., Leri, N., Yandam, F., Risris, S., Wahyupuji., Pertiwi, A., Jupri., Dista, U., Anita, S., Dimas, A., \& Yopie, A. (2014). Pedoman Penyusunan Rencana Teknis Pemanfataan Kawasan Konservasi Perairan. Kementrian Kelautan dan Perikanan, Jakarta.

Humaida, R. (2014). Strategy to Handle Resistance Of Antibiotics. Journal of Majority 3 (7) : 113-120.

Kennedy, P.S.J., Tobing, S.Z., Lumbantoruan, R., \& Tampubolon, E. (2019). Diskusi Tentang Peran Kearifan Lokal dalam Pemanfaatan Sumber Daya Laut dengan Kelompok Masyarakat Maluku Barat Daya. JPM Jurnal Pemberdayaan Masyarakat, 4(1): $355-164$.

https://doi.org/10.21067/jpm.v4i1.3063. 
Mahrus. (2014). Kontroversi Produk Rekayasa Genetika yang Dikonsumsi Masyarakat. Jurnal Biologi Tropis 14 (2) : 108-119.

Mansur, W., Kamal, M.M., \& Krisanti, M. (2013). Estimasi Limbah Organik dan Daya Dukung Perairan Dalam Upaya Pengelolaan Terumbu Karang di Perairan Pulau Semak Daun Kepulauan Seribu. Depik Jurnal Ilmu-ilmu Perairan, Pesisir dan Perikanan, 2(3): 141-153. https://doi.org/10.13170/depik.2.3.973

Moerad, S.K., Windiani, S., Mukhtar., \& Nurif, M. (2014). Pemetaan Sosial Budaya Masyarakat Desa Sumber Agung Kecamatan Pesanggaran Kabupaten Banyuwangi. Jurnal Sosial Humaniora, 7(1): 61-74. https://dx.doi.org/10.12962/j24433527.v7i1.596

Novita, M.Z., Soewardi, K., \& Pratiwi N.T.M., (2015). Penentuan Daya Dukung Perairan untuk Perikanan Alami (Studi Kasus: Situ Cilala, Kabupaten Bogor). Jurnal Ilmu Pertanian Indonesia (JIPI), 20(1): 66-71. https://journal.ipb.ac.id/index.php/JIPI/article/vi ew/9295

Nordiansyah, H., Ismail., \& Bakrie, I. (2016). Penilaian Efektifitas Pengelolaan Kawasan Konservasi di Kawasan Cagar Alam Padang Luway Kabupaten Kutai Barat. Jurnal AGRIFOR, XV(1): 43-54.

https://doi.org/10.31293/af.v15i1.1780

Peranginangin, L.S.U. (2014). Partisipasi Masyarakat Dalam Pengelolaan Kawasan Konservasi. Jurnal Kebijakan dan Administrasi Publik, 18(1): 66-78. https://doi.org/10.22146/jkap.6877

Pranata, R.T.H., \& Satria, A. (2015). Strategi Adaptasi Nelayan Terhadap Penetapan Kawasan Konservasi Perariran Daerah di Misool Selatan, KKPD Raja Ampat. Jurnal Kebijakan Sosial Ekonomi Kelautan dan Perikanan, 5(2): 113-128. http://dx.doi.org/10.15578/jksekp.v5i2.1022.

Prasita, V.D., Widigdo, B., Hardjowigeno, S., \& Budiharsono, S. (2008). Jurnal Ilmu-ilmu Perairan dan Perikanan Indonesia, 15(2): 95-102. https://doi.org/10.33378/jppik.v9i2.61.

Pratiwi, R. H. (2017). Mekanisme Pertahanan Bakteri Patogen Terhadap Antibiotik. Jurnal Pro-Life 4 (3) : 418-429.
Purnawan, S., Zaki, M., Asnawi, T.W., \& Setiawan, I. (2015). Studi Penentuan Lokasi Budidaya Kerapu Menggunakan Keramba Jaring Apung di Perairan Timur Simeulue. Depik Jurnal Ilmu-ilmu Perairan, Pesisir dan Perikanan, 4(1): 40-48. https://doi.org/10.13170/depik.1.1.2365

Purnomo, T., Hariyadi, S., \& Yonvitner. (2013). Kajian Potensi Perairan Dangkal untuk Pengembangan Wisata Bahari dan Dampak Pemanfataannya Bagi Masyarakat Sekitar (Studi Kasus Pulau Semak Daun sebagai Daerah Penunjang Kegiatan Wisata Pulau Pramuka Kabupaten Administrasi Kepulauan Seribu). Depik Jurnal Ilmuilmu Perairan, Pesisir dan Perikanan, 2(3): 172 183. https://doi.org/10.13170/depik.2.3.992

Rajab, M.A., Fahruddin, A., \& Setyobudiandi, I. (2013). Daya Dukung Perairan Pulau Liukang untuk Aktifitas Ekowisata Bahari. Depik Jurnal Ilmuilmu Perairan, Pesisir dan Perikanan, 2(3); 114125.

https: / /doi.org/10.13170/depik.2.3.854

Romadhon, A. (2014). Strategi Konservasi Pulau Kecil Melalui Pengelolaan Perikanan Berkelanjutan (Studi Kasus Pulau Gili Labak, Sumenep). Jurnal Kelautan, 7(2): 86-93. https://doi.org/10.21107/jk.v7i2.801

Syahrani. (2016). Penyusunan Program Desa Berdasarkan Pemetaan Sosial (Social Mapping) di Kecamatan Penajam Kabupaten Paser Utara. Jurnal Paradigma, 5(3): 160-182. http://dx.doi.org/10.52239/jp.v5i3.438

Utami, S.B., \& Pancasilawan. R.. (2017). Kolaborasi Dalam Pengelolaan Kawasan Konservasi Taman Buru Gunung Masigit Kareumbi Provinsi Jawa Barat. Jurnal Manajemen Pelayanan Publik, 1(1): 59-73. https://doi.org/10.24198/jmpp.v1i1.13550

Yulfiperus., Firman., \& Darwisito, S. (2018). Pemanfaatan Tongkol Jagung Sebagai Pengganti Dedak dalam Formulasi Pakan Ikan Ramah Lingkungan. Prosiding Seminar Nasional Perikanan dan Kelautan. 140-148.

Yulianda. (2008). Kajian Kesesuaian dan Daya Dukung Lingkungan Tambak Berbasis Spasial di Wilayah Pesisir Kabupaten Aceh Utara, Pantai Timur Provonsi NanggroeAceh Darussalam. Jurnal Ilmu-ilmu Perairan dan Perikanan Indonesia. $15(2)$ : 157-163. 